\title{
Synthesis of Carbon Supported Pd-Sn Catalysts by Ethylene Glycol Method for Ethanol Electrooxidation
}

\author{
Yunhua Li ${ }^{1}$, Yajun Wang ${ }^{1}$, Hongmin Mao ${ }^{2}$, Qiaoxia $\mathrm{Li}^{1, *}$ \\ ${ }^{1}$ Shanghai Key Laboratory of Materials Protection and Advanced Materials in Electric Power, College \\ of Environmental and Chemical Engineering, Shanghai University of Electric Power, 2103 Pingliang \\ Road, Yangpu District, Shanghai, 200090, China \\ ${ }^{2}$ Wuhan Product Quality Supervision \& Testing institute, No.5 Donger Road, Jinyin Lake, \\ Dongxihu District, Wuhan, Hubei, 430048, China \\ *E-mail: liqiaoxia@shiep.edu.cn
}

doi: $10.201964 / 2016.08 .18$

Received: 4 April 2016 / Accepted: 26 May 2016 / Published: 7 July 2016

\begin{abstract}
Carbon supported Pd-Sn catalysts (Pd-Sn/C-EG) were synthesized by an ethylene glycol method. The resulting catalysts exhibited high electrical catalytic activity for ethanol oxidation in alkaline solution. Transmission electron microscopyanalys was showed that the prepared Pd-Sn catalysts were uniformly dispersed on the carbon support with a mean particle size of $1.63 \mathrm{~nm}$. X-ray diffraction patterns for all samples indicated a fcc crystalline structure. The negative shift observed for Pd (111) suggested that Sn could shrink the Pd crystalline lattice. The electrocatalytic activity and long-term stability towards ethanol electrooxidation of the Pd-Sn/C-EG catalyst were superior to that of a commercially available $20 \mathrm{wt} . \% \mathrm{Pd} / \mathrm{C}$. More importantly, the oxidation peak current of the Pd-Sn/C-EG was found to be twice as large compared with that of $\mathrm{Pd} / \mathrm{C}$. This difference may be attributed to the uniform distribution of the prepared nanoparticles and the third body effect induced by addition of Sn onto the Pd surface. Furthermore, Sn doping can significantly provide the adsorption of $\mathrm{OH}$ species and speed up the ethanol oxidation reaction.
\end{abstract}

Keywords: ethanol electrooxidation; ethylene glycol method; Pd-based; Sn doping

\section{FULLTEXT}

(C) 2016 The Authors. Published by ESG (www.electrochemsci.org). This article is an open access article distributed under the terms and conditions of the Creative Commons Attribution license (http://creativecommons.org/licenses/by/4.0/). 